\title{
El ecoturismo como modelo internacional de desarrollo sostenible del turismo cultural
}

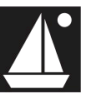

Javier de Esteban Curiel

Arta Antonovica Universidad Rey Juan Carlos

\section{RESUMEN}

El ecoturismo en cuanto modelo internacional del turismo cultural es responsable con el medio ambiente y tiene un carácter de sostenibilidad, lo cual beneficia a las comunidades locales. Sin embargo, no es simplemente sinónimo de turismo sostenible porque cuente con un enfoque medioambiental y cultural. Como afirma Hall (1994), la "pisada" o "huella" del ecoturista es en esencia igual que la de cualquier otro "turista de masas". No obstante, el ecoturismo parecer tener un futuro próspero, siempre y cuando permanezca a pequeña escala y se mantenga el control local. En este artículo se debate sobre el ecoturismo como una forma de turismo cultural y como un modelo internacional de desarrollo turístico válido para cualquier destino, se gestiona con criterios de sostenibilidad.

Palabras |Ecoturismo, turismo cultural, posmodernismo, modelos, CLAVE sostenibilidad.

Correos electrónicos: javier.deesteban@urjc.es•arta.antonovica@urjc.es 


\section{Introducción}

El profesor Alejandro López López (200 I: 207) comenta que “al comienzo de los años setenta aparecen nuevas aproximaciones al tema turístico desde perspectivas críticas y medioambientales. En dicha línea se expresa la revista Annals of Tourism Research que afronta cuestiones tan relevantes como la psicología del turista, el papel del ocio en la sociedad industrial urbana, la simbología de las vacaciones y hasta primeras expectativas respecto al medio ambiente". En el campo del turismo tuvieron lugar reuniones, congresos y foros, para debatir distintos aspectos de esta actividad, dando lugar también a diferentes declaraciones, como la de Manila, sobre el turismo mundial.

No obstante, es al comienzo de la década de los noventa cuando se introduce el carácter de sostenibilidad en el turismo. Las primeras referencias datan del $41^{\circ}$ Congreso de la Asociación Internacional de Expertos Científicos del Turismo (AIEST) celebrado en I99I. El turismo sostenible fue descrito como "aquel que mantiene un equilibrio entre los intereses sociales, económicos y ecológicos. El turismo debe integrar las actividades económicas y recreativas con el objetivo de la conservación de los valores naturales y culturales".

Después de la Conferencia Internacional de Río en 1992, ya comentada anteriormente, empiezan a aparecer multitud de aportaciones para la delimitación de la sostenibilidad en el turismo, como las realizadas por la Organización Mundial del Turismo (OMT) en 1993, en el documento titulado Tourism the year 2000 and beyond qualitative aspects, donde definió el concepto de turismo sostenible: "el desarrollo turístico sostenible responde a las necesidades de los turistas actuales y las regiones receptivas, protegiendo y agrandando las oportunidades del futuro. Se le representa como rector de todos los recursos de modo que las necesidades económicas, sociales y estéticas puedan ser satisfechas manteniendo la integridad cultural de los procesos ecológicos esenciales, la diversidad biológica y los sistemas en defensa de la vida”.

En ese mismo año se comienza a resaltar el proceso de la Agenda 2 I con una serie de aspectos prioritarios para la integración del turismo y el medio ambiente:

I. La minimización de los residuos. Evitar los vertidos y la acumulación de los mismos.

2. Conservación y gestión de la energía. Mediante el ahorro y la utilización de fuentes alternativas. 
3. Gestión de recursos del agua. Ahorro y no contaminación.

4. Gestión de las aguas residuales. No contaminación y reutilización.

5. Sustancias peligrosas. Petróleo, elementos radiactivos.

6. Transporte. Masificación. Contaminación y provocación de molestias.

7. Planeamiento y gestión del uso del suelo. Impacto urbanístico sobre la naturaleza.

8. Implicación de responsables y las comunidades locales en las cuestiones medioambientales.

9. Diseño para la sostenibilidad.

I0. Partenariado para el desarrollo sostenible.

En 1995 se lleva a cabo en Lanzarote la I Conferencia Mundial para el Turismo Sostenible auspiciada por diversas instituciones, entre las que cabe resaltar las Naciones Unidas, la OMT, y la Unión Europea (UE). El principal logro de la Conferencia fue la promulgación de la Carta del Turismo Sostenible compuesta por 18 principios que ponen las bases para una estrategia turística mundial fundada en el desarrollo sostenible.

De esta Carta del Turismo Sostenible de Lanzarote (1995), se puede extraer la definición del desarrollo turístico sostenible, según la cual... todo desarrollo turístico deberá fundamentarse sobre criterios de sostenibilidad, es decir, ha de ser soportable ecológicamente a largo plazo, viable económicamente y equitativo desde una perspectiva ética y social para las comunidades locales. El desarrollo sostenible es un proceso orientado que contempla una gestión global de los recursos con el fin de asegurar su durabilidad permitiendo conservar nuestro capital natural y cultural, incluyendo las áreas protegidas.

Por tanto, la confirmación definitiva de la relación entre la sostenibilidad y el turismo.

Al mismo tiempo que la Conferencia de Río, la Comisión Europea aprobó el V Programa Comunitario de Acción en Materia de Medio Ambiente y Desarrollo Sostenible, con el título "Hacia un desarrollo sostenible que planteaba la necesidad de integrar el medio ambiente en todas las políticas sectoriales de la UE y de sus Estados miembros". El Programa selecciona cinco sectores básicos en los que se deben aplicar las políticas de desarrollo sostenible: industria, energía, transporte, agricultura y turismo. 
Durante la II Cumbre para la Tierra de 1997, celebrada en Nueva York, el turismo es reconocido como un sector económico que necesita un desarrollo sostenible. El crecimiento esperado en el sector turístico, el aumento de la confianza de los países en desarrollo, incluidas las pequeñas islas-Estado, y la contribución del turismo como contribuyente (producto interno bruto) y empleador (empleo) en las economías locales, nacionales y regionales, subrayan la urgencia de prestar especial atención a la relación entre la protección-conservación ambiental y el turismo sostenible.

Llegados a esta punto, es factible reflexionar acerca de los conceptos que se han explicado hasta ahora. En concreto, se puede plantear cierta diferenciación entre dos términos en particular: el turismo sostenible y el desarrollo turístico sostenible. Según Holden (2000: 172), el "turismo sostenible pone el énfasis en el cliente $y$ en las consideraciones turísticas relacionadas con el marketing, $y$ así mantener el sector turístico. Mientras que el desarrollo turístico sostenible se basa en el turismo como vehículo para conseguir alcanzar el desarrollo sostenible, y por tanto recurriendo al turismo como una herramienta para lograr objetivos sociales y ambientales más amplios”. En consecuencia, el turismo sostenible no tiene por qué apreciar dimensiones sociales o ambientales. Se trata básicamente de que vengan más clientes para sostener o hacer crecer la actividad turística. Mientras que el desarrollo turístico sostenible tiene en cuenta el grado social y medioambiental. Parece, por tanto, más correcto y apropiado hablar, de esta forma, de desarrollo turístico sostenible.

En definitiva, es en la última década del siglo $x X$, cuando el concepto de sostenibilidad se aplica a todos los niveles del turismo: local, nacional, público, privado. La sostenibilidad ocupa, así, un eje central en cualquier organización turística, si bien para algunos autores críticos como Butler (1998: 27) esto se debe, más que a una verdadera concienciación, a las tres siguientes razones materialistas:"beneficios económicos, relaciones públicas y marketing". Asimismo, entre los principales espacios de acción del desarrollo turístico sostenible se da prioridad a las costas, las zonas rurales, las áreas urbanas y las islas, pues son los que tienen los recursos más frágiles (Smith, 2003: 77). Por último, entre la multitud de criterios que aparecen a la hora de evaluar la sostenibilidad del turismo, cabe mencionar los que recoge Pulido Fernández (2000), debido su carácter integral e integrado, expuestos en el cuadro $I$. 
Cuadro I. Criterios para evaluar la sostenibilidad del turismo

\begin{tabular}{|c|c|}
\hline Alojamiento & $\begin{array}{l}\text { - Gestión activa respecto al ahorro de agua y energía, el } \\
\text { tratamiento de aguas residuales y el reciclaje de basura } \\
\text { - Gestión de calidad en todas sus actividades: acogida, servi- } \\
\text { cios, equipamientos, instalaciones, promoción y comercia- } \\
\text { lización, etc. } \\
\text { - Incentivar la rehabilitación y promoción de viviendas tra- } \\
\text { dicionales frente a la nueva construcción } \\
\text { - Limitar la oferta de alojamiento de acuerdo con la } \\
\text { capacidad de carga de la zona }\end{array}$ \\
\hline Infraestructuras & 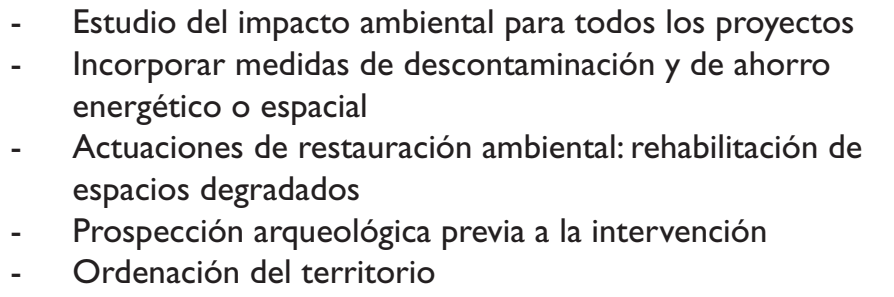 \\
\hline Energía & $\begin{array}{ll}\text { - } & \text { Reducir el consumo energético } \\
\text { - } & \text { Fomentar el empleo de energías alternativas } \\
\text { - } & \text { Auditorías energéticas }\end{array}$ \\
\hline Imagén urbana & $\begin{array}{ll}\text { - } & \text { Regulación del proceso urbanizador } \\
\text { - } & \text { Protección y valorización del patrimonio } \\
\text { - } & \text { Depuración de aguas residuales } \\
\text { - } & \text { Sistemas selectivos para la recogida de basura } \\
\text { - } & \text { Rehabilitar antes que construir } \\
\text { - } & \text { Mejora de la calidad ambiental a través de: } \\
\quad \text { descontaminación, control de ruidos, dotación de } \\
\text { - } \quad \text { Sequipamiento, señalización, depuración y restauración } \\
\text { - } \quad \text { Utilización de plantas autóctonas en zonas ajardinadas }\end{array}$ \\
\hline Paisaje & $\begin{array}{l}\text { - } \quad \text { Planificar y regular las actividades de los turistas en los } \\
\text { Espacios Nacionales Protegidos para evitar su degradación } \\
\text { Zonificación de usos } \\
\text { - } \quad \text { Reforestación con plantas autóctonas } \\
\text { - } \quad \text { Regenerar ríos y zonas degradadas } \\
\text { - } \quad \text { Plan de conservación paisajística }\end{array}$ \\
\hline
\end{tabular}

Continúa 
El ecoturismo como modelo internacional de desarrollo sostenible del turismo cultural

Cuadro I. CRiterios para eVAluar la sostenibilidad del tUrismo

(FINALIZA)

\begin{tabular}{|c|c|}
\hline Gastronomía & $\begin{array}{ll}\text { - } & \text { Fomentar la cocina autóctona } \\
\text { - } & \text { Incentivar el consumo de productos de la zona } \\
\text { - } & \text { Cooperar con los agricultores locales que apliquen } \\
& \text { técnicas de cultivo ecológicas } \\
\text { - } & \text { Premiar a las empresas que adopten medidas de } \\
& \text { protección ambiental }\end{array}$ \\
\hline $\begin{array}{l}\text { Tráfico de } \\
\text { vehículos }\end{array}$ & $\begin{array}{l}\text { - Plan integral de tráfico } \\
\text { - Restringir la circulación vial en espacios de elevado interés } \\
\text { ecológico o en centros urbanos de interés histórico o ar- } \\
\text { tístico } \\
\text { - Priorizar las zonas peatonales, el transporte público y el } \\
\text { uso de la bicicleta }\end{array}$ \\
\hline $\begin{array}{l}\text { Ocio de los } \\
\text { turistas }\end{array}$ & $\begin{array}{l}\text { - Amplia oferta cultural con participación de la población } \\
\text { local: descubrimiento de tradiciones, folclore, música, arte- } \\
\text { sanía, etc. } \\
\text { - Actividades beneficiosas para el medio ambiente, } \\
\text { educación ambiental, etc. } \\
\text { - Control de la frecuentación } \\
\text { - Amplia y variada infraestructura de uso público }\end{array}$ \\
\hline $\begin{array}{l}\text { Participación } \\
\text { ciudadana }\end{array}$ & $\begin{array}{l}\text { - Establecer cauces de participación de la población local en } \\
\text { el proceso de desarrollo turístico } \\
\text { - Campañas de concienciación ciudadana, etc. } \\
\text { - Preservación y mejora de la calidad de vida de la } \\
\text { población local } \\
\text { - Apoyo a la economía local } \\
\text { - Promoción del empleo local: nuevas oportunidades de } \\
\text { empleo }\end{array}$ \\
\hline $\begin{array}{l}\text { Información y } \\
\text { promoción }\end{array}$ & $\begin{array}{l}\text { - } \quad \text { Campaña eficaz de promoción de los avances ambientales } \\
\text { del municipio y de su preocupación por un desarrollo tu- } \\
\text { rístico de calidad } \\
\text { - } \quad \text { Sensibilización, educación y formación ambiental } \\
\text { - } \quad \text { Información sobre actividades no impactantes } \\
\text { - } \quad \text { Señalización del territorio } \\
\text { - } \quad \text { Exclusividad de la oferta turística } \\
\text { - } \quad \text { Se informará sobre los beneficios de la conservación del } \\
\text { - } \quad \text { Patrimonio y el desarrollo sostenible } \\
\text { Marketing y promoción responsable }\end{array}$ \\
\hline
\end{tabular}

Fuente: Pulido, 2000: 48-49 
Sostenibilidad del turismo cultural y ecoturismo desde la perspectiva posmodernista Como se ha señalado en los puntos anteriores, la sostenibilidad del desarrollo turístico se ha convertido en un objetivo cada vez más estratégico para muchos destinos. Se acepta comúnmente que la asociación constructiva entre la industria, los residentes locales y sus gobiernos son una condición necesaria para la sostenibilidad (Middleton, 1997). Los destinos deben preservar su futuro y buscar estrategias y técnicas de desarrollo sostenible. El turismo cultural normalmente depende de los recursos culturales y patrimoniales que están ligados a la fuerza económica de las comunidades locales. Para darle carácter de sostenibilidad al turismo cultural, las necesidades y valores de los residentes, proveedores y visitantes se deben ajustar con una planificación prudente, con el propósito de facilitar niveles aceptables de contacto entre residentes y visitantes (Derrett, 1996). Cuando el turismo se convierte en sostenible, se produce un incentivo económico inducido que permite la preservación de las zonas naturales para su uso de bajo impacto (Hassan, 2000).

Swarbrooke (1996) considera al turismo cultural como un sistema, e identifica los principales fundamentos para que este tipo de turismo tenga un desarrollo sostenible. En este sentido, el turismo cultural sostenible depende de los comportamientos y actitudes de diversos agentes como el gobierno, los turistas, las comunidades locales y otros que inciden en el sistema (véase figura I). Por otro lado, Pearce (1995) establece cuatro actividades necesarias para que el turismo cultural sea más sostenible:

I. Un énfasis en el marketing social, que tiene en cuenta la credibilidad y la aceptación por la comunidad de las imágenes de la cultura que se usan para la promoción turística (Morrison cit. en Pearce, 1995). La voz de la comunidad local se puede escuchar a través del marketing turístico al seleccionar representantes comunitarios para que investiguen las imágenes de su sociedad y se promocionen en el exterior de su zona (Pearce, 1995).

2. La obtención de información que analice con precisión las clases de experiencias culturales que se ofrecen a los turistas.

3. El desarrollo de una gama de oportunidades culturales que abarquen la diversidad de las necesidades de los visitantes y la preparación mental del contacto cultural.

4. El mejoramiento de las habilidades de investigación para evaluar y controlar la efectividad en la prestación de las instalaciones y los servicios: 
El ecoturismo como modelo internacional de desarrollo sostenible del turismo cultural

es decir, conocer las reacciones del mercado, y valorar las respuestas y actitudes de la comunidad local.

En suma, el turismo cultural, en su búsqueda de la sostenibilidad, debe hacer frente a las nuevas tendencias del mercado y adaptarse lo antes posible a ellas, en particular a dos: por un lado, al mayor número de turistas que se desplazan por motivos culturales; $y$ por otro, al hecho de que, gracias a las tecnologías, los turistas culturales se trasladan cada vez más a lugares recónditos que antes eran desconocidos o inaccesibles. En este sentido, un tipo de recurso o forma de turismo cultural -planteado por Smith (2003:37) - que se está desarrollando en los últimos años como modelo de desarrollo sostenible, por su responsabilidad con el medio ambiente y su sensibilidad por la cultura, es el ecoturismo.

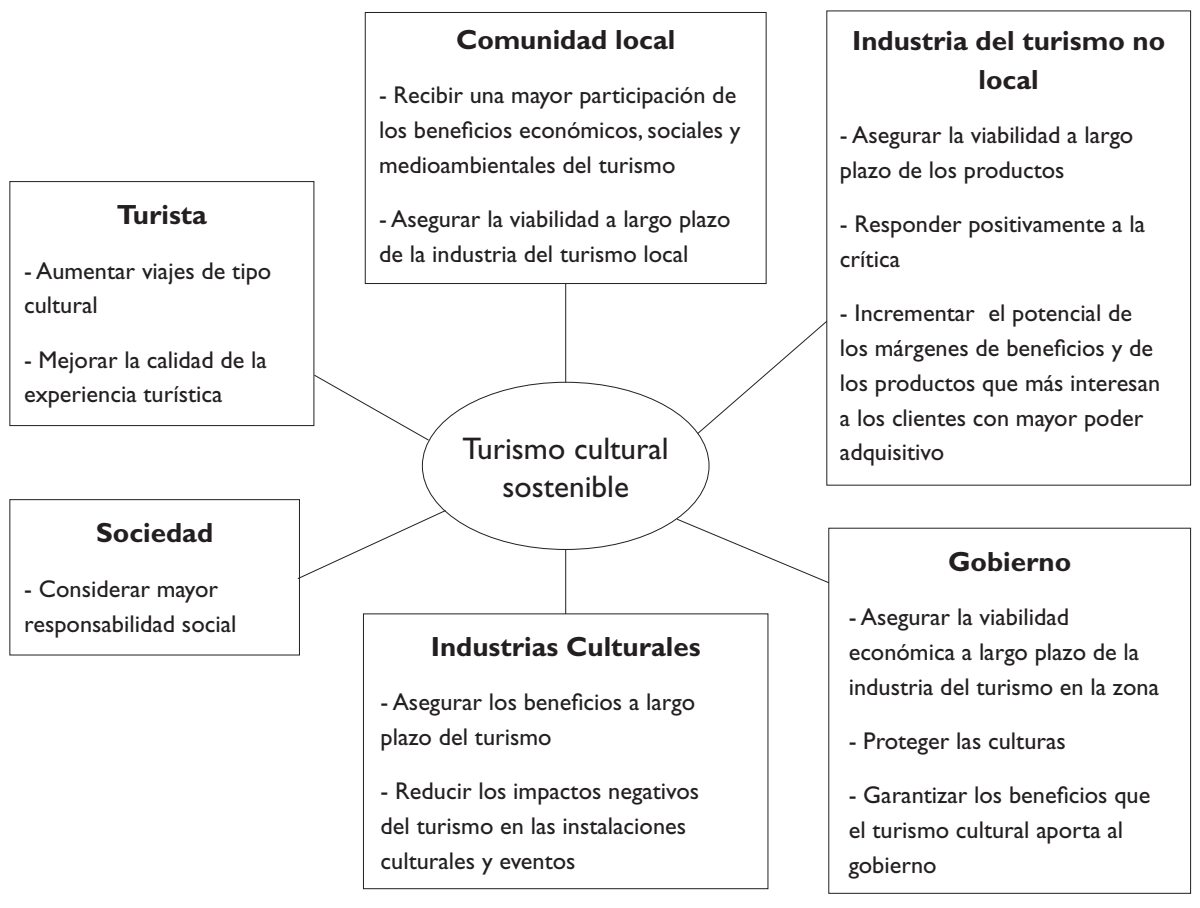

Fuente: Swarbrooke, 1996b: 252

FIGURA I. DifERENTES FUNDAMENTOS DEL TURISMO CULTURAL SOSTENIBLE 
Smith (1997: I4I) postula que en algunas de las formas de viajes culturales posmodernas, como el ecoturismo, el turismo de aventura o el de naturaleza,"se establece una predisposición especial en los individuos por la observación de recursos escasos y únicos". En efecto, estos tipos de turistas suelen viajar hacia destinos idílicos que tengan unos paisajes naturales e intactos. En este tenor, The International Ecotourism Society (I99I) define el ecoturismo como "un viaje responsable a zonas naturales que conserva el medio ambiente y sostiene el bienestar de los habitantes locales". La OMT (2002), por su parte, alega que el ecoturismo incluye no sólo aquellas actividades realizadas para la contemplación de la naturaleza, sino también aquellas que se realizan para conocer las culturas tradicionales de las zonas naturales. De este modo, el ecoturismo se puede definir como un subconjunto del turismo cultural, o, de acuerdo con Smith (2003: 37), como un tipo de turismo de cultura indígena. Entre algunas de las principales actividades que se incluyen dentro del ecoturismo, se pueden citar la visita a la jungla, a la selva tropical o al desierto; el alpinismo de montaña; el senderismo; un safari, o unas vacaciones ornitológicas, $y$ otras más.

\section{Conclusiones}

Así pues, el ecoturismo es responsable con el medio ambiente y tiene un carácter de sostenibilidad, lo cual beneficia a las comunidades locales. Sin embargo, no es simplemente sinónimo de turismo sostenible porque tenga un enfoque medioambiental y cultural. Como afirma Hall (1994), la "pisada" o "huella" del ecoturista es en esencia igual que la de cualquier otro "turista de masas". Empero, los ecoturistas suelen tener más dinero y mayor poder adquisitivo, según apuntan Hawkins y Khan (1994: 193):

El ecoturismo tiene que ver principalmente con personas adineradas que viajan de países desarrollados a países en desarrollo. Estos ecoturistas pertenecen a un grupo con un gran poder adquisitivo, con más tiempo de ocio y dinero que gastar. Buscan sobre todo experiencias naturales.

Por ende, el ecoturismo tiene un futuro próspero, siempre y cuando permanezca a pequeña escala y se mantenga el control local. En este orden, se podría decir lo mismo respecto a las otras formas de turismo cultural, como el turismo rural, el musical, el de ciudades históricas, etc., por lo que el turismo cultural, con carácter general, se puede considerar como un modelo de 
desarrollo turístico válido para cualquier destino, si se gestiona con criterios de sostenibilidad. No obstante, esto dependerá del contexto sociopolítico de los destinos, si prefieren crecimiento o desarrollo, por lo cual las generalizaciones no son siempre útiles. En definitiva, el futuro del desarrollo del turismo cultural sostenible estriba, sin lugar a dudas, en una planificación previa y en las buenas prácticas a escala mundial que se ejecuten al respecto. Sólo así se podrán proteger esos pocos "paraísos perdidos" que quedan en la Tierra,y mejorar aquellos que ya han empezado a erosionarse en nombre del turismo cultural.

\section{FUENTES CONSULTADAS}

Butler, R.W. (1998). "Sustainable Tourism: Looking Backwards in order to Progress?”, en C.M. Hall y A.A. Lew (eds.). Sustainable Tourism:A Geographical Perspective. Harlow:Addison-Wesley Longman, 25-34.

Carta del Turismo Sostenible de Lanzarote (1995). Información disponible en la siguiente página web: http://www.turismo-sostenible.org/docs/ Carta-del-Turismo-Sostenible.pdf

Derrett, R. (1996)."The Tourism Culture of Cultural Tourism:Planning through Community Consultation”, en M. Robinson, N. Evans y P. Callaghan (eds.). Tourism and Culture:Tourism and Cultural Change. Sunderland: Centre for Travel and Tourism/Business Education Publishers, 6I-73. The International Ecotourism Society (199I) (online) Disponible en la página web:http://www.ecotourism.org/site/c.orLQKXPCLmF/b.4835303/k. BEB9/What_is_Ecotourism__The_International_Ecotourism_ Society.htm

Esteban Curiel,J. de (2008). Turismo cultural y medio ambiente en destinos urbanos. Madrid: Dykinson.

Hall, C.M. (1994). Tourism and Politics: Policy, Power and Place. Chichester: John Wiley \& Sons.

Hassan, S.S. (2000). "Determinants of Market Competitiveness in an Environmentally Sustainable Tourism Industry”. Journal of Travel Research, 38 (3), 293-300.

Hawkins, D.E.y M.M. Khan (1994). “Ecotourism Opportunities for Developing Countries”, en W.F.Theobald (ed.). Global Tourism:The Next Decade. Oxford: Butterworth-Heinemann, | 9 |-204. 
Holden,A. (2000). Environment and Tourism: Routledge Introductions to Environment. Londres: Routledge.

López López,A. (200I). “El medio ambiente y las nuevas tendencias turísticas: referencia a la región de Extremadura”. Observatorio Medioambiental, 4, 205-25I.

Middleton, V. (1997). “Sustainable Tourism: A Marketing Perspective”, en M.J. Stabler (ed.). Tourism and Sustainability. Wallingford: CAB International. OMT (2002). "Resultados preliminares del programa de investigación de la OMT sobre los mercados generadores de ecoturismo". FITUR-Sesión de Ecoturismo para América Latina. Año Internacional del Ecoturismo (AIE) 2002 [en línea]. Organización Mundial del Turismo. Disponible en: http://www.worldtourism.org/sustainable/lYE/fairs/fitur/huescar.htm

Pearce, P. (1995) "From Culture Shock and Culture Arrogance to Culture Exchange: Ideas towards Sustainable Sociocultural Tourism”. Journal of Sustainable Tourism, 3 (3), I43-I 53.

Pulido Fernández, J.I. (2000). Ordenación, planificación y gestión del desarrollo turístico en espacios naturales protegidos. Madrid: Escuela Universitaria de Turismo de la Universidad de Alcalá, Documentos de Trabajo.

Smith, M.K. (2003). Issues in Cultural Tourism Studies. Londres: Routledge.

Smith,V. (1997). “The Four Hs of Tribal Tourism:Acoma-A Pueblo Case Study”, en C. Cooper y S.Wanhill (eds.). Tourism Development: Environmental and Community Issues. Chichester:John Wiley \& Sons, I4I-I 52.

Swarbrooke, J. (1996). "Towards a Sustainable Future for Cultural Tourism: A European Perspective”, en M. Robinson, N. Evans y P. Callaghan (eds.). Tourism and Culture: Managing Cultural Resources for the Tourist. Sunderland: Centre for Travel and Tourism/Business Education Publishers, 227-255. 